\title{
ANÁlISE FÍSICO-QUÍMICA DAS ÁGUAS DE POÇOS NA BACIA HIDROGRÁFICA DO TUCUNDUBA - BELÉM-PA
}

\section{ARTIGO ORIGINAL}

BERINO, Michele de Oliveira ${ }^{1}$

MATTA, Milton Antônio da Silva ${ }^{2}$

BERINO, Michele de Oliveira. MATTA, Milton Antônio da Silva. Análise físicoquímica das águas de poços na bacia hidrográfica do Tucunduba - Belém-PA. Revista Científica Multidisciplinar Núcleo do Conhecimento. Ano 05, Ed. 06, Vol. 05, pp. 91-110. Junho de 2020. ISSN: 2448-0959, Link de acesso: https://www.nucleodoconhecimento.com.br/meio-ambiente/aguas-de-pocos

\section{RESUMO}

A bacia hidrográfica do Tucunduba (BHT), localiza-se numa área de periferia da região metropolitana de Belém. É caracterizada por apresentar problemáticas sociais históricos herdados, em decorrência, do tipo de processo de ocupação territorial vivenciados, em décadas passadas; sem planejamento que visasse a não aglutinação das residências sobre as áreas de riscos, ou ambientalmente impróprias de serem ocupadas, o que tem acarretado em prejuízos para o índice de desenvolvimento humano local, contaminação do meio ambiente e também dos recursos hídricos. Por se tratar de uma região hidrogeológica com boa produção de água subterrânea nos primeiros vinte metros de profundidade da Formação Barreira, a população está captando água do aquífero livre que é ambientalmente vulnerável às contaminações

${ }^{1}$ Geóloga (UFPA) Especialista em Planejamento e Manejo integrado dos Recursos Hídricos (UFPA); Mestranda em Hidrogeologia pela Universidade Federal do Pará, Instituto de Geociências, Programa de Pós graduação em Recursos Hídricos (PPRH). 2 Doutor em Hidrogeologia (UFPA); Pesquisador e Professor Titular pela Universidade Federal do Pará. 
superficiais. Análises físico-químicas dessas águas revelam resultados de pH em 4,92 (média), nitrogênio amoniacal elevado de $2,4 \mathrm{mg} / \mathrm{L}$ e 2,33 $\mathrm{mg} / \mathrm{L}$ nesta ordem; foi detectado o nitrito em $1,05 \mathrm{mg} / \mathrm{L}$, nitrato numa concentração de 14,47 , fosfato com média de $0,28 \mathrm{mg} \cdot \mathrm{L}^{-1}$, entre outros parâmetros analisados, que em conjunto atestam que as águas da BHT são improprias para o consumo, devido estarem altamente impactadas pelos processos antropogênicos locais. Com os elementos que foram identificados, na área de estudo, durante as visitas ao campo (lixo, esgotos, fossas irregulares, poços de captação de água mal construídos ou abandonados) foi confeccionado um modelo representativo das plumas de possível contaminação das águas subterrâneas locais.

Palavras-chave: Água, BHT, contaminação, poços, saúde.

\section{INTRODUÇÃO}

A água é um bem essencial à vida e muito vulnerável às contaminações naturais e antrópicas, sendo esta última a que tem acarretado maiores prejuízos aos recursos hídricos. Hoje houve-se falar em crise da água no Brasil e, é fato que em regiões onde há escassez da água haverá conflitos pelo seu uso. Segundo Capobianco (2007) a água consiste em um recurso natural de valor inestimável que constitui um insumo indispensável à produção e, um recurso estratégico no desenvolvimento econômico, sendo esta vital para a manutenção dos ciclos biológicos, geológicos e químicos que mantêm em equilíbrio os ecossistemas terrestres.

O consumo humano de água ocorre por quatro meios principais distintos: abastecimento público, através das redes sistemáticas de distribuição; abastecimento próprio a partir de poços profundos, rasos ou poços amazonas (cacimba); águas meteóricas quando os níveis de chuvas locais são favoráveis e abastecimento por carro pipa.

Estudos realizados por Hirata e Ferreira (2001) revelaram que as águas subterrâneas superficiais da Bacia Hidrográfica do Alto Tietê (BAT) estão sobre forte influência de contaminantes como: Lixões, indústrias químicas, postos de combustíveis e resíduos 
domiciliares como esgoto e foças clandestinas; segundo este, os lixões e aterros sanitários, na maioria das vezes, são responsáveis por algum impacto em aquífero em nosso País; assim este estudo aponta o fato dos contaminantes antrópicos constituírem riscos às águas superficiais e subterrâneas das bacias hidrográficas que se encontrem em situação de vulnerabilidade.

A Bacia Hidrográfica do Tucunduba (BHT) localizada no Município de Belém (PA) é uma área fruto de um processo de ocupação desorganizada, por se tratar de uma área de pouco interesse por parte da população da classe média local, as políticas de desenvolvimento social são praticamente inexistentes. O seu processo de ocupação histórico, inicia em 1930, devido a situação econômica da época o governo não interferiu; neste período as terras da bacia eram utilizadas, principalmente, para atividades agropastoris. Já a partir de 1940 houve uma redução das terras de cotas altas, as áreas menos atrativas com a da BHT foram ocupadas pelas famílias menos favorecidas financeiramente. Na década de 50 era evidente a ocupação das terras da BHT por atividades comerciais, indústrias, instalação de portos privados para embarque e desembarque de mercadorias e serrarias. A década de 60 foi marcada pela criação da Universidade Federal do Pará (UFPA) e o conjunto habitacional Montepio. Na década de 70 as terras da Bacia passaram para responsabilidade da Companhia de Desenvolvimento e Administração da Área Metropolitana de Belém (CODEM). Os anos de 80 foram marcados pelo processo de verticalização das áreas centrais da cidade de Belém, este fato acarretou com a inserção cada vez mais intensa das áreas de baixadas na BHT, aumentando o processo de favelização e exclusão socioeconômica (ALMEIDA, et al., 2004).

\section{LOCALIZAÇÃO E ACESSO}

A área selecionada para estudo localiza-se a Sudeste da cidade de Belém/Pará, Figura 1, no distrito administrativo do Guamá, conforme a Lei No 7682 de 05/01/1994. 
Figura 1: Localização da área de estudo.

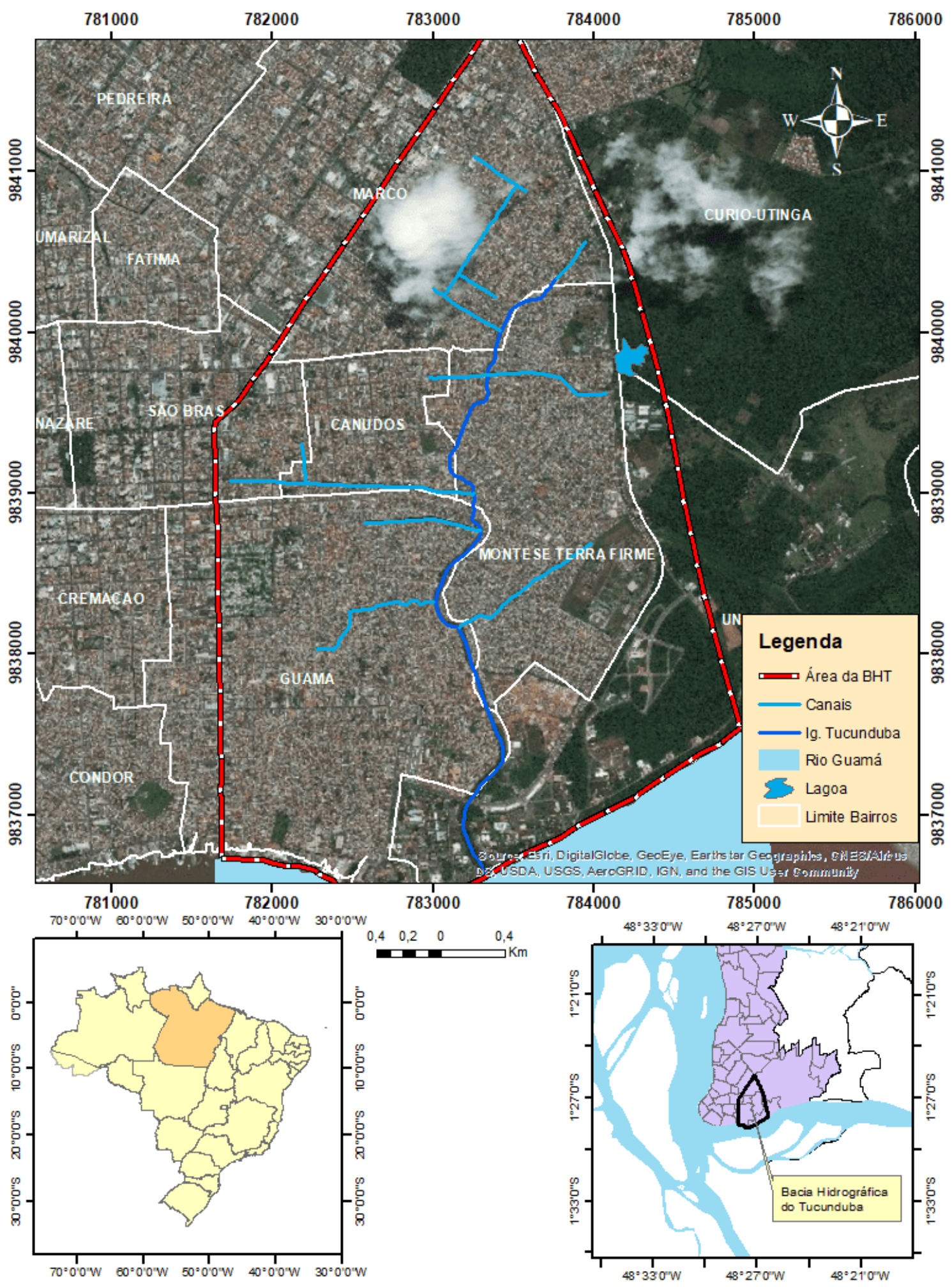

Fonte: autor. 
É delimitada pelas bacias de Murutucum, Una e Estrada Nova. Situada na região de baixo platô amazônico, caracterizada por apresentar terrenos de cotas baixas, o que favorece o constante processo de alagamento de suas ruas e avenidas em decorrência do alagamento de suas Bacias hidrográficas durante período de intensas chuvas (SANTOS, 2010).

A capital paraense conta com uma área da unidade territorial de 1.059,458 $\left(\mathrm{km}^{2}\right)$, população estimada em 2015 de 1.439.561, densidade demográfica de 1.315,26 (hab/km²). Índice de desenvolvimento humano (IDH) para últimas três décadas: 1991 foi de 0,562, 2000 foi de 0,644 e de 2010 de 0,746 (IBGE, 2014).

Dentre as áreas de baixada de Belém, distribuídas entre as 14 bacias hidrográficas existentes na capital, destaca-se a bacia hidrográfica do igarapé Tucunduba, com uma área de $10,55 \mathrm{~km}^{2}$, é considerada a quarta maior bacia hidrográfica da capital; abrange três distritos administrativos: DAGUA, DABEL e DAENT (BELÉM, 2000).

A área da Bacia abrange sete bairros: Guamá, São Braz, Marco, Canudos, CurióUtinga, Universitário e Terra Firme; com uma população de aproximadamente 198.350 habitantes, da qual cerca de $80 \%$ moram em áreas alagadas. O principal acesso se dá pelas avenidas Bernardo Sayão, Perimetral, Almirante Barroso, José Bonifácio e João Paulo II. No aspecto físico, a área do Tucunduba apresenta-se semelhante a um arco, de um lado ocupada por residências de alvenaria e de outro, por instituições com vegetação típica, sendo circundada por muitas casas tipo palafitas, acessíveis por meio de estivas e passagens de aterro (SANTOS, 2010).

\section{MATERIAIS E MÉTODOS}

A abordagem metodológica teve início a partir de um levantamento bibliográfico a respeito da área selecionada para estudo (BHT). Com as informações do banco de dados de poços do SIAGAS (disponível no site da CPRM), onde são encontradas informações sobre os poços perfurados, devidamente cadastrados na grande Belém, foram selecionados os poços de interesse dentro da área de estudo. As etapas de trabalhos foram divididas em três. 
Na primeira etapa, para construir um arquivo de dados de poços da área de estudo, foram utilizadas informações disponíveis no SIAGAS e, posteriormente, para complementar, foram realizadas visitas técnicas em campo, para coletar informações de poços não cadastrados, tais como: localização, tipo, profundidade e o nível de água no poço e com esses dados foi confeccionado o mapa com a localização dos poços na Figura 2.

$\mathrm{Na}$ segunda etapa foram levantadas as informações de possíveis fontes potenciais de contaminação das águas superficiais, fluviais e subterrâneas a partir de visitas locais e, o registro fotográfico das fontes contaminantes expostas a céu aberto para a simples complementação dos dados qualitativos.

Figura 2: Mapa com cadastro de poços do SIAGAS e os poços visitados na BHT

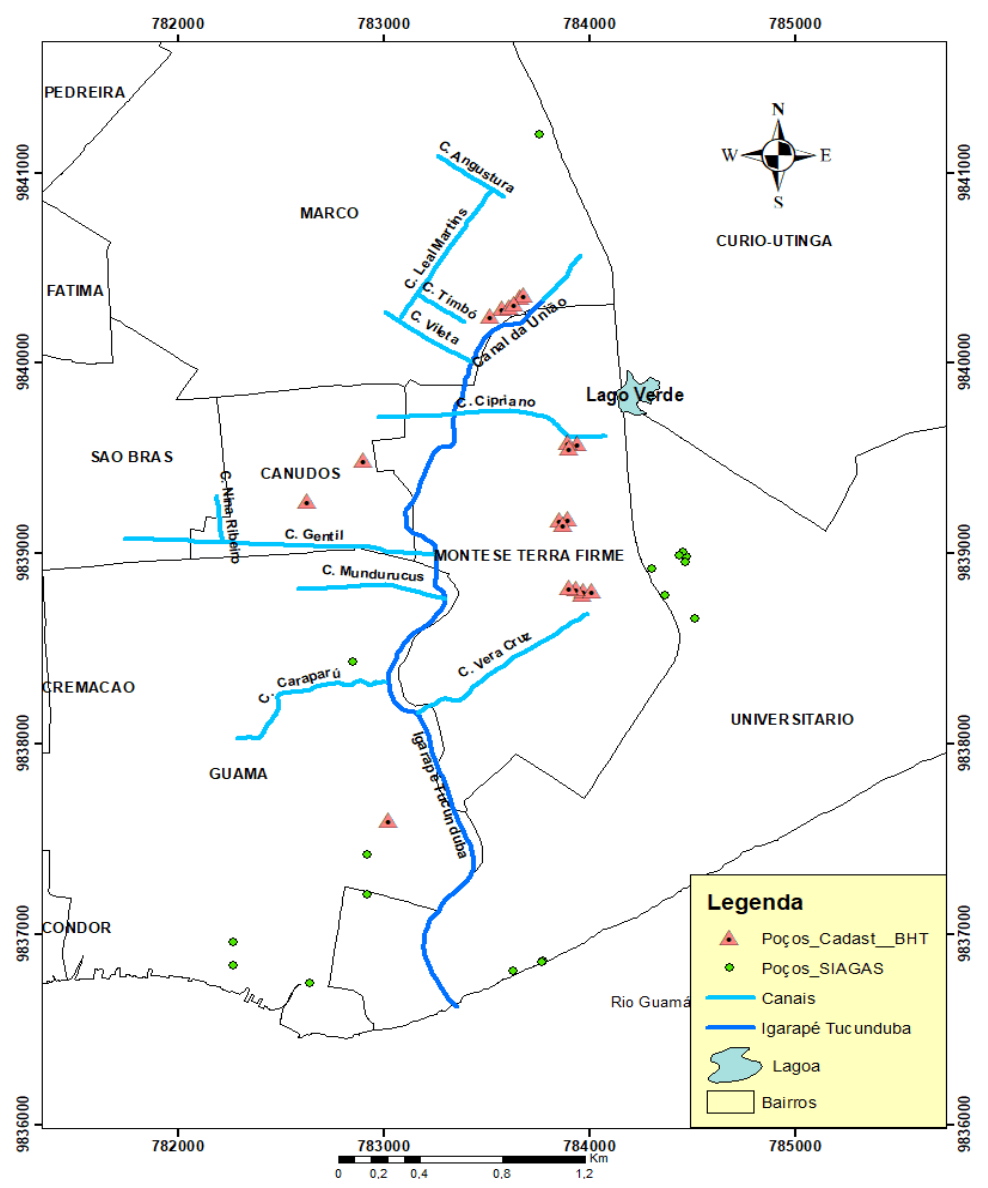

Fonte: autor. 
$\mathrm{Na}$ terceira etapa foram realizadas a caracterização socioambiental da área, entrevistas dos moradores e as coletas de água nos oito poços (com o apoio técnico do Instituto Evandro Chagas, Belém) selecionados para avaliar as características físico química desta água. A proposta inicial seria utilizar a técnica da estatística representativa do espaço amostral por quantidade de domicílios presentes na área de estudo, porém houve resistência por parte de alguns moradores, que desconfiados, achavam tratar-se de alguma política governamental ou fiscalização para regularizar o uso da água de poços, dessa forma o espaço amostral foi bastante reduzido. Assim, os poços visitados foram pré-selecionados utilizando a ferramenta Google Earth Pro com intuito de obter uma representação mais uniforme quanto à disposição geográfica destes, mas a seleção final foi definida de acordo com a aceitação do proprietário em participar deste estudo. As ferramentas de trabalho utilizadas foram o GPS, Trena, Medidor de nível estático, máquina fotográfica, formulário de cadastro dos poços e caderneta de anotações das informações adicionais da área.

\section{CARACTERIZAÇÃO DA ÁREA DE ESTUDO DA BHT}

A Bacia hidrográfica do Tucunduba (BHT) abrange os bairros da Terra Firme, Guamá, universitário, canudos e parte de São Brás e Marco. Durante as visitas em campo, observou-se que estes bairros apresentam sérios problemas ambientais com a questão da falta de saneamento eficiente, aliado a essa deficiência ainda soma-se a falta de consciência de parte dos moradores da área que continuam a despejar todo tipo de lixo doméstico, esgoto, eletrônicos em desuso, entre outros, tornando-se, assim, uma grande lixeira a céu aberto, na Figura 3 ( $A$, B e C), canal da av. Cipriano Santos, sentido Terra Firme - São Brás. 
Figura 3: A-B-C e D, acúmulo de lixo no interior do canal e na via de acesso, av. Cipriano Santo.

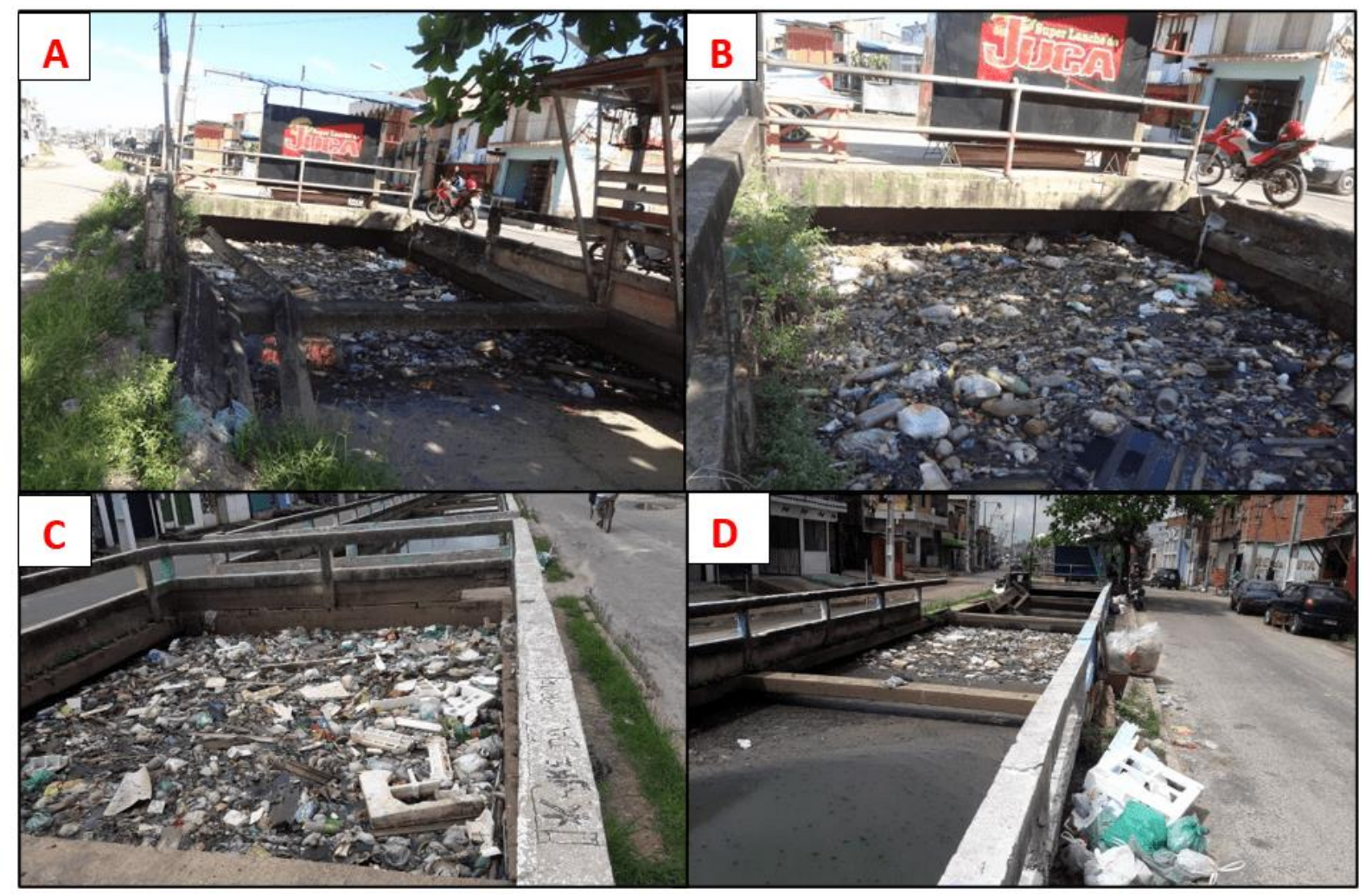

Fonte: autor.

A questão do lixo é um agravante que podemos observar, praticamente, em todas as esquinas de Belém, a falta de educação ambiental junto ao serviço ineficiente de coleta de lixo, e praticamente inexistência de campanhas voltadas ao não dispense de lixo nas vias e canais, agravam essa problemática histórica. É uma causa tão urgente quanto os investimentos em saúde e educação, uma vez que, essa situação verificada nos canais e vias, contribuem para a proliferação de pragas, doenças nas pessoas e, contaminam solo, água e os animais.

Durante o processo de prática de campo, foram visitados os locais que o igarapé Tucunduba não se encontra retificado, como as vias da Celso Malcher, Tucunduba, Nossa Senhora das Graças, Dois de Junho e Cipriano Santos. Foram registradas várias situações de vulnerabilidade de aquíferos, boa parte dos moradores ainda convivem com a velha problemática de saneamento inexistente, residências do tipo 
palafitas com acesso por pontes estreitas de madeiras quase em ruínas, vias estreitas com muito entulho, lixo e lama na Figura 4 - A, B, C, D.

Figura 4: Em A, B, C e D, observa-se trechos do igarapé Tucunduba com muito lixo, caroços de açaí usados como aterro, serragens e pedaços de madeiras descartadas pelas serrarias locais

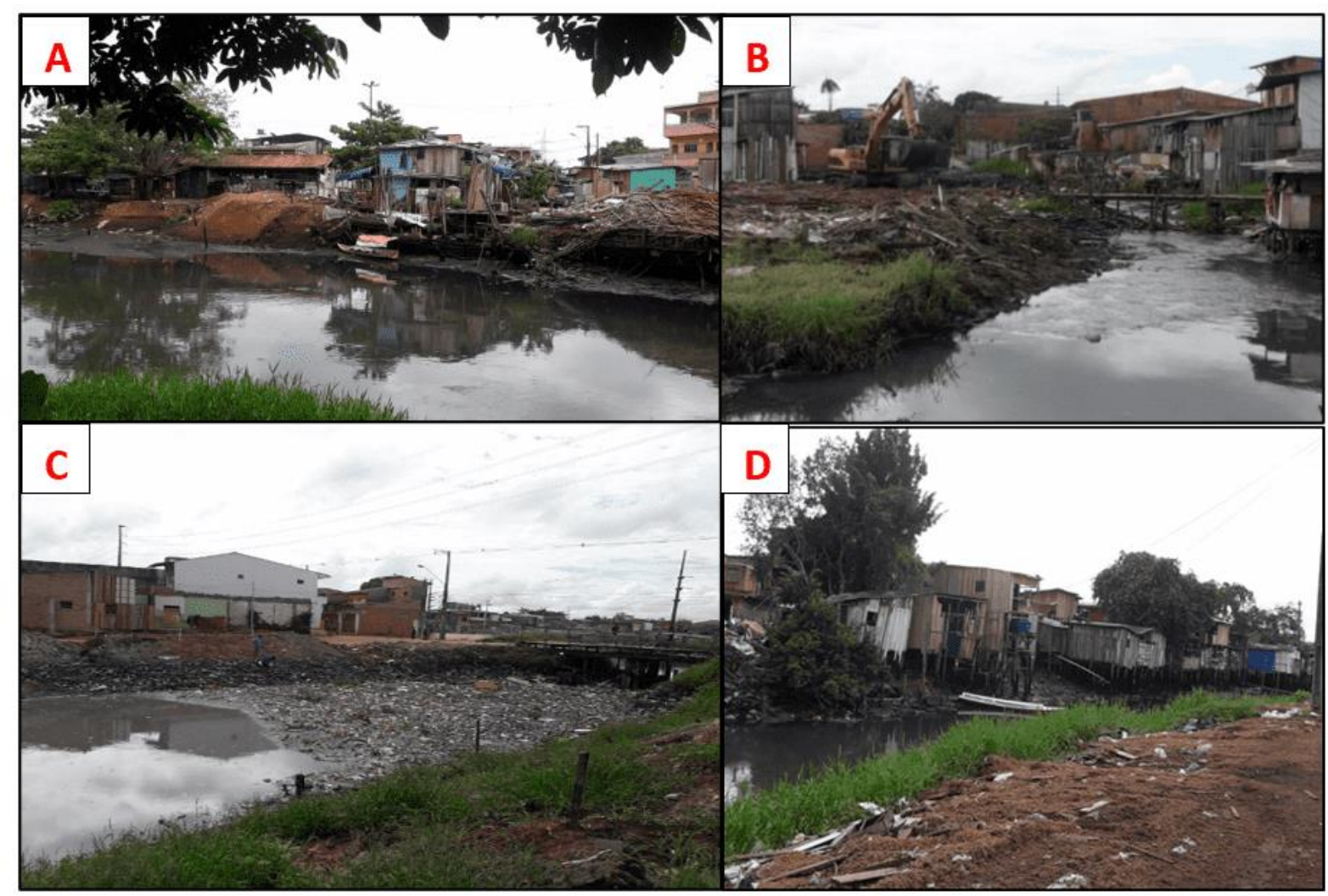

Fonte: autor

\section{RESULTADOS}

Do total de 36 poços estudados na Tabela 1, oito foram selecionados e submetidos à análise físico química pelo Instituto Evandro Chagas (Belém-Pará), esses dados foram sintetizados na Tabela 2, que ilustra os quinze parâmetros analisados. 
Tabela 1: Dados dos poços estudados.

\begin{tabular}{|c|c|c|c|c|c|c|c|}
\hline Poço & UTM N & UTM S & $\begin{array}{l}\text { Prof. } \\
\text { poço }\end{array}$ & $\begin{array}{l}\text { Cota } \\
\text { Top }\end{array}$ & $\begin{array}{l}\text { Nível } \\
\text { água } \\
(\mathrm{m})\end{array}$ & $\begin{array}{l}\text { Nível } \\
\text { estático }\end{array}$ & Identificação \\
\hline 1 & 9840287 & 783574 & 17 & 6 & 2,13 & 3,87 & Sr. Edérico \\
\hline 2 & 9840241 & 783520 & 6 & 5 & 1,78 & 3,22 & Sr. Laércio \\
\hline 3 & 9839527 & 783982 & 36 & 5 & 0,32 & 4,68 & Sra. Diva \\
\hline 4 & 9839174 & 783855 & 3 & 6 & 0,88 & 5,12 & Sra. Raimunda \\
\hline 5 & 9838786 & 783969 & 23 & 6 & 0,42 & 5,58 & Sra. Esmaelina \\
\hline 6 & 9839491 & 782899 & 22 & 10 & 3,35 & 6,65 & Sra. Fátima \\
\hline 7 & 9838443 & 782626 & 18 & 4 & 1,85 & 2,15 & Sr. Ayrton \\
\hline 8 & 9837598 & 783025 & 10,53 & 8 & 0,28 & 7,72 & Vila Macapá \\
\hline 9 & 9840194 & 783618 & 30 & 5 & 0,36 & 4,64 & Sra. Francisca \\
\hline 10 & 9840180 & 783595 & 15 & 5 & 0,31 & 4,69 & Sra. Telma \\
\hline 11 & 9838830 & 783853 & 10 & 7 & 1,85 & 5,15 & Sra. Emiliana \\
\hline 12 & 9840440 & 783773 & 15 & 8 & 2,9 & 5,1 & Sr. Michel \\
\hline 13 & 9840409 & 783742 & 19 & 8 & 4,4 & 3,6 & Sr. Paulo \\
\hline 14 & 9840343 & 783660 & 18 & 7 & 4,84 & 2,16 & Sr. Valdemir \\
\hline 15 & 9838827 & 783858 & 15 & 7 & 0,6 & 6,4 & Sra. Maria \\
\hline 16 & 9838812 & 783885 & 28 & 6 & 0,9 & 5,1 & Sr. Edivan \\
\hline 17 & 9838833 & 783820 & 20 & 7 & 1 & 6 & Sra. Andréia \\
\hline 18 & 9838807 & 783918 & 21 & 6 & 0,44 & 5,56 & Sr. Antônio \\
\hline 19 & 9839210 & 783988 & 18 & 7 & 0,92 & 6,08 & Sr. Pedro \\
\hline 20 & 9839179 & 783957 & 15 & 8 & 1,1 & 6,9 & Sra. Cláudia \\
\hline 21 & 9836744 & 782639 & 18 & 6 & 3,26 & 2,74 & $\begin{array}{l}\text { Irineu Castro } \\
\text { Ltda. }\end{array}$ \\
\hline 22 & 9838659 & 784512 & 19 & 6 & 0 & 6 & COSANPA \\
\hline 23 & 9837205 & 782918 & 28 & 6 & 7,3 & $-1,3$ & Viação Guajará \\
\hline 24 & 9836960 & 782269 & 24 & 6 & 3,5 & 2,5 & $\begin{array}{l}\text { Supermix } \\
\text { Cimentos }\end{array}$ \\
\hline
\end{tabular}




\begin{tabular}{|c|c|c|c|c|c|c|c|}
\hline 25 & 9838650 & 782579 & 24 & 6 & 5,7 & 0,3 & $\begin{array}{l}\text { Palamaz } \\
\text { alimentos }\end{array}$ \\
\hline 26 & 9841200 & 783757 & 36 & 18 & 13,4 & 4,6 & Posto ICCAR \\
\hline 27 & 9836861 & 783777 & 150 & 7 & 6,69 & 0,31 & $\begin{array}{l}\text { UFPA Belém } \\
\text { 4BE 03PA }\end{array}$ \\
\hline 28 & 9836805 & 783629 & 250 & 7 & $-1,71$ & 8,71 & $\begin{array}{l}\text { UFPA Belém } \\
\text { P4 }\end{array}$ \\
\hline 29 & 9836861 & 783777 & 258 & 7 & 5 & 2 & $\begin{array}{l}\text { UFPA Belém } \\
\text { P3 }\end{array}$ \\
\hline 30 & 9838980 & 784471 & 254 & 5 & 1 & 4 & $\begin{array}{l}\text { COSANPA } \\
\text { Terra firme } 4\end{array}$ \\
\hline 31 & 9838918 & 784302 & 297 & 9 & 0,59 & 8,41 & $\begin{array}{l}\text { COSANPA- } \\
\text { TEF-10 }\end{array}$ \\
\hline 32 & 9838955 & 784467 & 105 & 7 & $-1,9$ & 8,9 & $\begin{array}{l}\text { COSANPA } \\
\text { Terra Firme } 5\end{array}$ \\
\hline 33 & 9838781 & 784368 & 268 & 8 & 2,4 & 5,6 & $\begin{array}{l}\text { COSANPA } \\
\text { Terra Firme } 7\end{array}$ \\
\hline 34 & 9836855 & 783770 & 79 & 7 & 6,1 & 0,9 & UFPA Belém \\
\hline 35 & 9838430 & 782850 & 100 & 4 & $-4,35$ & 8,35 & COSANPA \\
\hline 36 & 9838986 & 784436 & 89,65 & 5 & -1 & 6 & $\begin{array}{l}\text { COSANPA- } \\
\text { PERIMETRAL }\end{array}$ \\
\hline
\end{tabular}

Fonte: autor. 
Tabela 2: Resultado das análises Físico-química.

\begin{tabular}{|c|c|c|c|c|c|c|c|c|c|c|}
\hline $\begin{array}{l}\text { Parâmetro } \\
\text { Analisado }\end{array}$ & P01 & P02 & P03 & P04 & P05 & P06 & P07 & P08 & Unidade & $\begin{array}{l}\text { Portaria } \\
2914 / 11 \\
\text { do M.S. }\end{array}$ \\
\hline $\mathrm{pH}$ & 3,92 & 4,44 & 3,98 & 6,88 & 4,78 & 4,07 & 5,24 & 6,05 & NA & 6,0 à 9,5 \\
\hline $\begin{array}{c}\text { Temperatura } \\
\left({ }^{\circ} \mathrm{C}\right)\end{array}$ & 27,75 & 29,68 & 27,38 & 27,84 & 27,82 & 28,47 & 27,57 & 28,92 & ${ }^{\circ} \mathrm{C}$ & Ambiental \\
\hline Condutividade & 178 & 232 & 39 & 713 & 290 & 391 & 302 & 512 & $\mu \mathrm{S} / \mathrm{cm}^{2}$ & N/D \\
\hline $\begin{array}{l}\text { Sólidos T. } \\
\text { Dissolvidos } \\
\text { (TDS) }\end{array}$ & 89 & 116 & 20 & 356 & 145 & 196 & 151 & 256 & $\mathrm{mg} / \mathrm{L}$ & 1000 \\
\hline $\begin{array}{l}\text { Sólidos T. em } \\
\text { Suspensão } \\
\text { (STS) }\end{array}$ & $<L Q$ & $<\mathrm{LQ}$ & $<\mathrm{LQ}$ & $<\mathrm{QQ}$ & $<\mathrm{LQ}$ & $<\mathrm{LQ}$ & $<\mathrm{LQ}$ & 16 & $\mathrm{mg} / \mathrm{L}$ & N/D \\
\hline Cor aparente & $<L Q$ & $<\mathrm{LQ}$ & $<L Q$ & 52 & 37 & 11 & $<L Q$ & 99 & $\begin{array}{l}\mathrm{mg} \mathrm{Pt} \\
\mathrm{Co} / \mathrm{L}\end{array}$ & 15 \\
\hline $\begin{array}{c}\text { Alcalinidade } \\
\text { Total }\end{array}$ & 20 & 20 & 20 & 140 & 10 & 10 & 30 & 110 & $\mathrm{mg} / \mathrm{L}$ & N/D \\
\hline $\begin{array}{l}\text { Nitrogênio } \\
\text { Amoniacal }\end{array}$ & $<L Q$ & $<\mathrm{LQ}$ & $<\mathrm{LQ}$ & 1,29 & $<\mathrm{LQ}$ & 0,37 & 2,4 & 2,33 & $\mathrm{mg} / \mathrm{L}$ & 1,5 \\
\hline Cloreto & 23,6 & 37,79 & 4,3 & 56,17 & 44,74 & 36,17 & 31,78 & 49,6 & $\mathrm{mg} / \mathrm{L}$ & 250 \\
\hline Fluoreto & $<L Q$ & $<\mathrm{LQ}$ & $<\mathrm{LQ}$ & $<\mathrm{QQ}$ & $<\mathrm{LQ}$ & $<L Q$ & $<\mathrm{LQ}$ & $<\mathrm{LQ}$ & $\mathrm{mg} / \mathrm{L}$ & 1,5 \\
\hline Nitrito & $<\mathrm{LQ}$ & $<\mathrm{LQ}$ & $<\mathrm{LQ}$ & 1,05 & $<\mathrm{LQ}$ & $<\mathrm{LQ}$ & $<\mathrm{LQ}$ & $<\mathrm{LQ}$ & $\mathrm{mg} / \mathrm{L}$ & 1 \\
\hline Nitrato & 5,84 & 5,02 & 1,14 & 2,52 & 6,9 & 14,47 & 4,54 & 0,32 & $\mathrm{mg} / \mathrm{L}$ & 10 \\
\hline Sulfato & 5,73 & 4,78 & 0,48 & 34,63 & 9,47 & 22,85 & 33,39 & 21,05 & $\mathrm{mg} / \mathrm{L}$ & 250 \\
\hline Fosfato & 0,23 & 0,3 & 0,28 & 0,4 & 0,27 & 0,29 & 0,19 & 0,33 & $\mathrm{mg} / \mathrm{L}$ & N/D \\
\hline Dureza & 14,22 & 12,9 & 7,14 & 166,03 & 28,21 & 44,92 & 24,69 & 88,12 & $\mathrm{mg} / \mathrm{L}$ & 500 \\
\hline
\end{tabular}

Fonte: Modificado do Instituto Evandro Chagas (IEC, 2018).

- $\mathrm{pH}$ (potencial Hidrogeniônico):

Das oito amostras, seis apresentaram $\mathrm{pH}$ abaixo do valor de referência estabelecido pela portaria 2914/11 do Ministério da Saúde (MS). É de suma relevância compreender o impacto na saúde com relação ao consumo de águas contaminadas e ácidas, como se pode observar na tabela 1, a maioria apresenta um caráter ácido, o que culmina em inúmeros prejuízos a qualidade de vida das pessoas envolvidas nesse consumo. 
O P01, por exemplo, apresentou o menor pH, sendo de 3,92 e o P04 apresentou o maior $\mathrm{pH}$ de 6,88; com média em 4,92. Segundo Matta (2002), o pH ácido é uma característica comum das águas amazônicas e, isto se dá pela cobertura vegetal densa que, a partir de sua decomposição nos solos, gera ácidos orgânicos que apresentam grupos carboxílicos $(-\mathrm{COOH})$, que dissociam, liberando $\mathrm{H}^{+}$, e reduzindo o $\mathrm{pH}$ das águas

Em estudos realizados por Gomes et al, $(2016$, p.5) foi constatado que valores mais elevados de $\mathrm{pH}$ geralmente se encontram em águas com predominância dos íons $\mathrm{Na}+$ e $\mathrm{Ca}++$ ou em águas ricas em bicarbonatos; as águas poluídas geralmente são mais ácidas. $\mathrm{O}$ pH ácido das águas podem causar doenças como gastrite, câncer gástrico e restrições nos usos gerais para as indústrias.

Ainda segundo Gomes et al. (2016) outras características importantes a considerar para resultados de $\mathrm{pH}$ baixo, é o fato de que estas águas ficam mais susceptíveis a ligações com metais como Al, Fe e Mn e, sua acidez pode advir da contaminação por efluentes domésticos.

O P02 que apresentou o segundo menor valor de $\mathrm{pH}$, representa um risco alto porque é comunitário, abastece pelo menos 200 famílias, segundo informações de seu proprietário, diariamente pessoas da comunidade coletam a água desta fonte em garrafões de 20 litros para consumo direto, seus usuários acreditam tratar-se de uma água boa para a saúde.

- Temperatura (T):

Todas as amostras analisadas apontaram temperatura normal, de acordo com as normas técnicas da portaria $2914 / 11$ do MS, que a temperatura deve ser a ambiental.

- Condutividade:

Nos valores de condutividade houve discrepâncias em relação à média que ficou em 332,12 $\mu \mathrm{S} / \mathrm{cm}^{2}$; O P03 apontou o menor valor para este parâmetro (39 $\left.\mu \mathrm{S} / \mathrm{cm}^{2-}\right)$, considerada uma condutividade muito baixa $(<50 \mu \mathrm{S} / \mathrm{cm})$, podendo ser associado à 
condição natural dos aquíferos. Em contrapartida, valores de condutividade acima de $100 \mu \mathrm{S} / \mathrm{cm}$ correspondem a concentrações de cloreto e nitrato acima dos valores definidos como o que ocorreu nas sete amostras $(\mathrm{P} 01=178, \mathrm{P} 02=232, \mathrm{P} 04=713$, P05 $=290$, P06 $=391$, P07 $=302$ e P08 =512 de (DE ASSIS et al., 2017).

- Sólidos Totais Dissolvidos (STD):

Segundo De Assis et al., (2017), o aumento da condutividade elétrica é acompanhado pelo aumento dos sólidos totais dissolvidos, assim o valor discrepante do P04 = 356 mg/L em relação à média que foi de $166,1 \mathrm{mg} / \mathrm{L}$ mostra uma relação do valor da condutividade com o valor do STD, pois a condutividade de uma água indica a sua capacidade de transmitir corrente elétrica, em função da presença de sustâncias dissolvidas, estas se dissociam em ânion e cátion, justificando o fato da ocorrência do alto valor de condutividade no P04 $=713 \mu \mathrm{S} / \mathrm{cm}^{2}$ ter sido acompanhado também de alto valor no STD $=356 \mathrm{mg} / \mathrm{L}$.

- Cor aparente:

O valor de referência para cor aparente na portaria 2914/11 do MS é de $15 \mathrm{mg} \mathrm{Pt}$ Co/L. O valor médio obtido nas amostras que possibilitaram a detecção desse parâmetro (P04, P05 e P08) foi de 66,66 mg Pt Co/L, valor médio muito alto, segundo Souza et al., (2004), o parâmetro cor aparente alto é um aspecto negativo na aparência da água. Contudo, isso não apresenta risco à saúde humana; no entanto, valores muito elevados, como na ocorrência do P08 $=99 \mathrm{mg} \mathrm{Pt} \mathrm{Co/L,} \mathrm{pode} \mathrm{ser}$ associado a uma elevada quantidade de substâncias dissolvidas, como o ferro, argilas, matéria orgânica em decomposição e, a presença de esgotos domésticos e industriais.

\section{- Alcalinidade Total:}

Segundo Farias (2006), uma água com característica alcalina é aquela que apresenta a capacidade de neutralizar um ácido, no entanto, se uma água é alcalina não significa necessariamente que o pH do meio deve ser superior a 7. A água subterrânea com pH inferior a 7 pode ter, em sua composição, alguns sais que neutralizam ácidos e, 
por isso, ter alguma alcalinidade calculável. Os íons carbonato e bicarbonato favorecem uma água de caráter mais alcalino, enquanto os íons cloreto, sulfato e nitrato fazem o contrário.

A média de alcalinidade foi de $45 \mathrm{mg} / \mathrm{L}$, com valores discrepantes no P04 = $140 \mathrm{mg} / \mathrm{L}$ e no P08 $=110 \mathrm{mg} / \mathrm{L}$, estas duas amostras apresentaram os mais altos valores de $\mathrm{pH}$, sendo 6,88 e 6,05 respectivamente. Segundo Piratoba et al., (2017), alcalinidade não tem um significado sanitário, com exceção de quando ela ocorre devido a hidróxidos, ou quando contribua na qualidade de sólidos totais. Assim, os valores altos nos resultados de alcalinidade para o P04 e P08, estão mais condicionados ao fator pH destes, que foram os mais altos se comparados à média de $\mathrm{pH}=4,92$.

- Nitrogênio Amoniacal:

O P07 e P08, apresentaram teor de nitrogênio amoniacal elevado de 2,4 mg/L e 2,33 $\mathrm{mg} / \mathrm{L}$ respectivamente, valor acima do limite tolerável pela Portaria 2914/11 do MS. O nitrogênio amoniacal é a primeira etapa da decomposição da matéria orgânica, sua presença está relacionada a contaminação recente; podendo estar correlacionado as construções precárias dos poços, e também, a falta de proteção do aquífero (ALABURDA e NISHIHARA,1998 apud SILVA e ARAÚJO, 2003, p.9).

\section{- Cloreto:}

Os cloretos $(\mathrm{Cl}-)$ geralmente se encontram presentes e todas as águas e habitualmente estão associados ao sódio. Dentre suas principais características estão: alta solubilidade, altamente deliquescente, muito estável em solução e dificilmente se precipita. A alta solubilidade e o lento movimento das águas subterrâneas provocam um aumento gradativo do teor dos cloretos das áreas de recarga, em direção as áreas de descarga. As águas subterrâneas apresentam geralmente teores inferiores a $100 \mathrm{mg} / \mathrm{L}$. São bons indicadores de poluição por lixão ou aterros sanitários (Feitosa et al., 2008). A média de Cloretos nas oito amostras ficou em 35,5 mg/L, os valores discrepantes ocorreram no P03 (4,3 mg/L) e no P04 
(56,17mg/L), como esses valores estão dentro do determinado pela portaria 2914/11 do MS, não oferecem risco a saúde humana.

- Fluoreto:

Este parâmetro, nas amostras estudadas, ficou abaixo do limite de quantificação.

- Nitrito:

Das oito amostras estudas, apenas a do P04 apresentou 1,05 mg/L nitrito, sendo uma quantidade acima do recomendado pela portaria 2914/11 do MS. Segundo Cardoso, Pinheiro e Ribeiro (2017), a presença de nitrito na água é associada a contaminação recente, oriunda de matéria orgânica ou da decomposição biológica a partir da ação de microrganismos sobre o nitrogênio amoniacal; os íons de nitritos, presentes na água destinada ao consumo humano, apresenta um efeito mais rápido que o nitrato e, se ingerido diretamente, pode ocasionar no organismo humano a metemoglobinemia, o que independe da idade do consumidor.

- Nitrato:

No P06 foi detectada a presença de nitrato numa concentração de 14,47 que é um valor bem acima do recomendado pela portaria $2914 / 11$ do MS, as altas concentrações de nitrato em águas oriundas de poços artesianos normalmente são provenientes de uma perfuração irregular e sem o devido acompanhamento técnico pelo profissional habilitado (hidro geólogo), da localização do poço, do uso exagerado de fertilizantes próximo ao local de perfuração do poço, ou da ausência de um tratamento adequado dos dejetos animais, ou mesmo humanos.

De acordo com Silva e Araújo (2003), o Nitrato é o produto final da estabilização aeróbia do nitrogênio orgânico, indicando contaminação antiga. Segundo informações da OPS ${ }^{[3]}$ (2000 apud SILVA e ARAÚJO, 2003, p.2):

"O consumo de água contaminada por agentes biológicos ou físico-químicos tem sido associado a diversos problemas de saúde. Algumas epidemias de doenças 
gastrointestinais, por exemplo, têm como fonte de infecção a água contaminada. Essas infecções representam causa de elevada taxa de mortalidade em indivíduos com baixa resistência, atingindo especialmente idosos e crianças menores de cinco anos".

- Sulfato:

Segundo Silva e Migliorini (2014), o sulfato (SO4 ${ }^{-2}$ ) é um componente importante na interpretação da qualidade da água; se presente em grandes quantidades, pode ser indicativo de contaminação por esgoto doméstico, industrial ou práticas agrícolas. Nas amostras analisadas a média para este parâmetro foi de 16,5 mg/L, logo estão abaixo do valor de referência da portaria 2914/11 do MS.

- Fosfato:

Não existe na legislação brasileira valores de referências para a presença de fosfato na água subterrânea. Em estudos realizados por Fineza (2008), mostra que em águas não contaminadas, as concentrações de íons fosfato são baixas $\left(0,01\right.$ a $\left.0,05 \mathrm{mg} \cdot \mathrm{L}^{-1}\right)$, em decorrência da fácil fixação e baixa solubilidade de compostos fosfatados no solo, logo, as perdas por lixiviação são desprezíveis; as concentrações acima de 0,05 mg.L${ }^{1}$ podem estar relacionadas a atividades antrópicas, como a produção de efluentes domésticos, a presença de sistemas sépticos, dejetos de animais e pesticidas. $\mathrm{E}$ segundo a OMS (Organização Mundial de Saúde), o valor de 0,1 mg.L-1 a 0,05 mg.L1 é o limite aceitável da fração de fosfato nas águas naturais não poluídas (BRASIL, 2006).

Nas oito amostras estudas a média para o fosfato foi de $0,28 \mathrm{mg} \cdot \mathrm{L}^{-1}$, um valor considerado alto ao comparar com os valores estabelecidos pela Organização Mundial de Saúde e Fineza (2008), de forma isolada, os valores das oito amostras para fosfato estão acima do recomendado; assim, conclui-se que estas águas estão impactadas por ação antrópica. 


\section{- Dureza}

Segundo Brasil (2006), a dureza indica a concentração de cátions multivalentes em solução na água, os mais frequentemente associados à dureza são os íons de cálcio e magnésio $\left(\mathrm{Ca}^{2+}, \mathrm{Mg}^{2+}\right)$ e, em menor escala, o íon de ferro $\left(\mathrm{Fe}^{2+}\right)$, íon de manganês $\left(\mathrm{Mn}^{2+}\right)$, íon de estrôncio $\left(\mathrm{Sr}^{2+}\right)$ e íon de alumínio $\left(\mathrm{Al}^{3+}\right)$. Ainda segundo Brasil (2006), a dureza pode ser classificada como dureza carbonato ou dureza não carbonato, o que depende do ânion com o qual ela está associada. A origem da dureza, nas águas, pode ser natural (por dissolução de rochas calcáreas, ricas em cálcio e magnésio) ou antrópica (lançamento de efluentes). A dureza da água é representada em $\mathrm{mg} / \mathrm{L}$ de equivalente em carbonato de cálcio ( $\mathrm{CaCO})$ e pode ser classificada em:

- mole ou branda: $<50 \mathrm{mg} / \mathrm{L}$ de $\mathrm{CaCO}$;

- dureza moderada: entre $50 \mathrm{mg} / \mathrm{L}$ e $150 \mathrm{mg} / \mathrm{L}$ de CaCO3;

- dura: entre $150 \mathrm{mg} / \mathrm{L}$ e $300 \mathrm{mg} / \mathrm{L}$ de CaCO3; e

- muito dura: $>300 \mathrm{mg} / \mathrm{L}$ de $\mathrm{CaCO}$.

Nas oito amostras analisadas, não houve valores de dureza acima do recomendado pela portaria 2914/11 do MS. Ao tomar a classificação de Brasil (2016), a mostra do P01, P02, P03, P05, P06 e P07 se classificam como água mole; a amostra do P04 fica na água dura e P08 como dureza moderada.

\section{DISCUSSÕES}

Durante a caracterização da área, foram observados diversos elementos que contribuem para a poluição e contaminação do solo e dos recursos hídricos; entre esses foram identificados: lixões irregulares a céu aberto (orgânicos, inorgânico, rejeitos, eletrônico de vários tipos e restos de construções), fossas do tipo sumidouro, ausência de saneamento adequado, canais e vias que são utilizados como lixeiras e poços do tipo amazonas abandonados. 
Figura 5: Modelo representativo das plumas de contaminação de fontes diversas em subsuperfície (corte transversal).

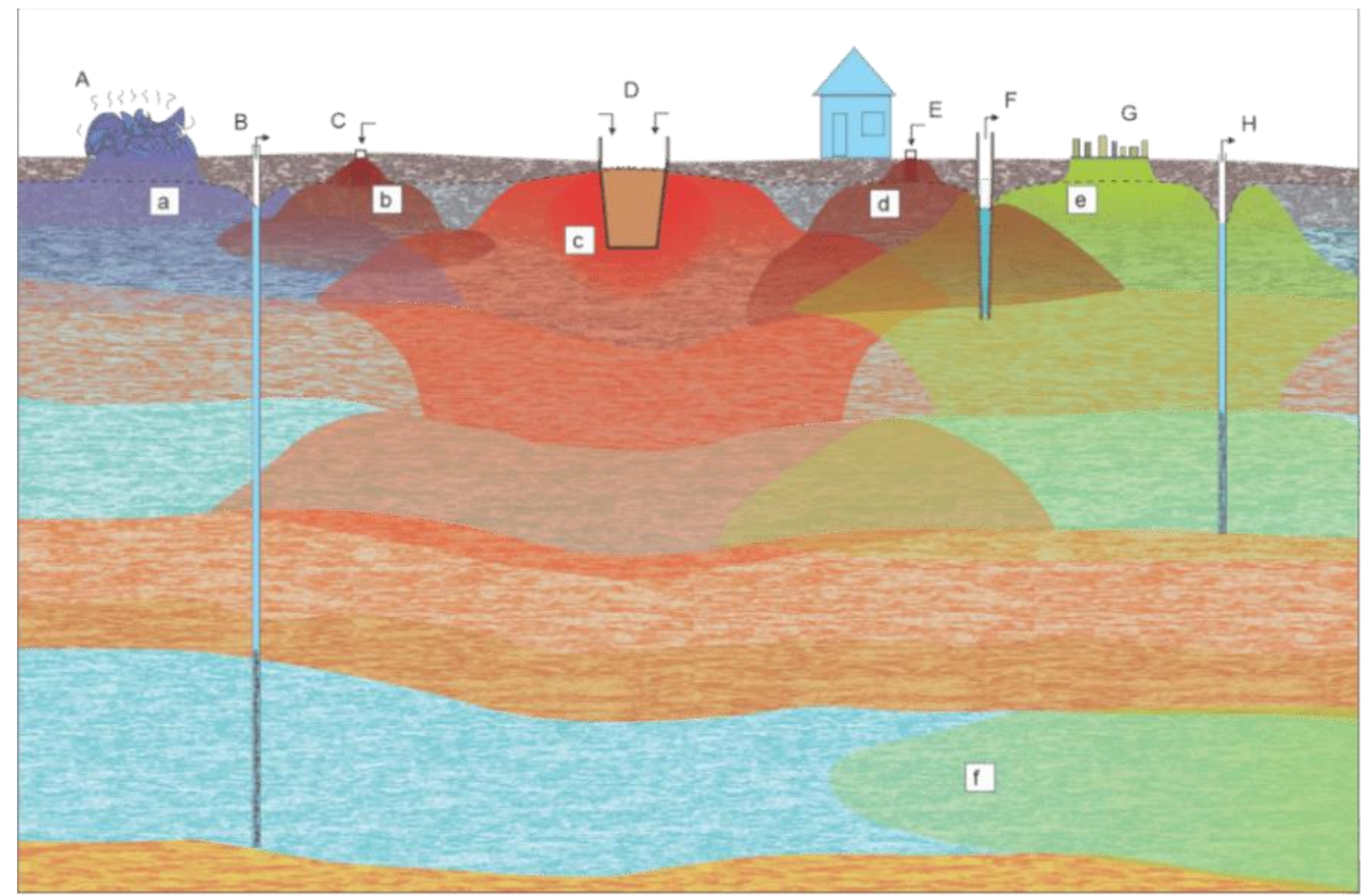

Fonte: autor

A ausência de controle e ações efetivas sobre estes elementos, poluidores dos recursos hídricos e do meio ambiente, geram impactos negativos para a população local e todo seu entorno; visto que as águas meteóricas e pluviais funcionam como um meio de transporte para os contaminantes e certamente comprometendo a qualidade das águas dos igarapés, lagos, rios e das águas subterrâneas superficiais. Na Figura 5 é apresentado um modelo de sugestivo de possível contaminação do ambiente, com os elementos identificados na BHT.

O modelo da Figura $5^{[4]}$ foi construído didaticamente com o auxílio da ferramenta CoreIDRAW - 2019, a escala vertical foi exagerada para facilitar a visualização. Este é baseado em furos de estaca raiz e, num perfil geofísico de poço do Setor 7 da Cosanpa (Captação Terra Firme). 
Considerando os dados do furo e do poço, construiu-se o modelo de camadas sobrepostas com variação de argilas, silte e areia. Do topo à base, o modelo é estimado em $25 \mathrm{~m}$, onde cada camada apresenta teores variados de material do tipo argilosos, siltosos e arenosos. As argilas acima de 7 metros apresentaram características mais orgânicas, o que sugere uma bacia de preenchimento do sistema fluvial (Guamá-Tucunduba).

Representa em A, os lixões; C e E são fossas; D é canal; G são indústrias, estes elementos representam as fontes de contaminantes. As letras $\mathrm{B}$ e $\mathrm{H}$ são poços tubulares; a letra F identifica um poço amazonas. As letras a, b, c, d, f, g, h e f, identificam as plumas de contaminação oriunda das fontes diversas. Observa-se que estas plumas podem interagir e intensificar o nível de contaminação local.

\section{CONCLUSÕES}

Neste trabalho, a região hidrogeológica conhecida por Bacia Hidrográfica do Tucunduba (BHT), foi analisada quanto ao Planejamento, manejo dos recursos hídricos e ocupação territorial. Além da pesquisa teórica e por meio de imagens de satélite (Google Earth Pro), foram realizados estudos da qualidade físico-química da água de poços rasos, em parceria com o Instituto Evandro Chagas (Belém); no resultado das análises, realizadas em águas de poços rasos, pertencentes aos moradores cadastrados, por meio de questionários, indicaram estar altamente impactadas.

A população local utiliza água do aquíferos livre que corresponde aos primeiros vinte metros de profundidade da formação Barreiras, os quais são desprotegidos ambientalmente e altamente vulneráveis às contaminações locais antropogênicas. Uma vez que os poços caseiros, captam água da primeira unidade aquífera, que na maioria das vezes é boa produtora.

A partir da análise dos resultados obtidos, conclui-se que pela própria natureza fisiográfica da $\mathrm{BHT}$ e, pela ocupação desordenada, a presença de fossas do tipo sumidouro, despejos de lixo constante e esgoto, de forma irregular nos canais de 
drenagem que estão interligados ao igarapé do Tucunduba, torna as águas superficiais da bacia impróprias ao consumo humano.

\section{REFERÊNCIAS}

ALMEIDA, F. Magalhães; MATTA, M. A. da Silva; DIAS, E. R. França; BANDEIRA I. C. Nascimento; PRADO, Joyce Brabo do; FIGUEIREDO, A. Batista de. Estudos hidrogeológicos da bacia hidrográfica do Tucunduba-Belém/PA, como base para uma proposta alternativa de abastecimento de ÁGUA. XIII Congresso Brasileiro de Águas Subterrâneas, 2004. Disponível em: < https://aguassubterraneas.abas.org > Acesso em 29 de Maio de 2016.

BELÉM. Prefeitura Municipal de Belém. Relação de Projetos Contratados com a Caixa Econômica Federal/FGTS - Pró-Saneamento - Serviço Autônomo de Água e Esgoto de Belém. Belém: PMB, 2000.

BRASIL. Vigilância e controle da qualidade da água para consumo humano. Ministério da Saúde, Secretaria de Vigilância em Saúde. - Brasília: Ministério da Saúde, 2006. 212 p. - (Série B. Textos Básicos de Saúde).

CAPOBIANCO, J.P.R. “Importância da água”. Disponível em: <http://mundovestibular.com.br/articles/569/1/IMPORTANCIA-DA AGUA/Paacutegina1.html> 2007. Acessado em 10 de Setembro de 2018.

DE ASSIS, Davison Márcio S.; DE LIMA, Aldaiane B.; DA SILVA, Emerson Renato M.; SILVA, Antonio dos S.; BARBOSA, Ivan Carlos da C. Avaliação dos Parâmetros Físico-Químicos da Água de Abastecimento em Diferentes Bairros do Município de Salvaterra (Arquipélago do Marajó, PA). Rev. Virtual Química, 2017, vol. 9, n5, 1825-1839.

FARIAS, Maria Sallydelandia Sobral de. Monitoramento da Qualidade da Água na Bacia Hidrográfica do Rio cabelo. Tese de doutorado, Universidade Federal de Campina Grande. Campina Grande, Paraíba, 2006. 
FINEZA, Adonai Gomes. Avaliação da contaminação de águas subterrâneas por cemitérios: Estudo de caso de Tabuleiro - MG, Brasil. 2008. 63f. Dissertação (mestrado). Universidade Federal de Viçosa, Curso de Engenharia Civil, Viçosa/MG. 2008.

GOMES, Maria da Conceição Rabelo; CAVALCANTE, Itabaraci Nazareno; SILVA, Mariane Pinto da. Análise qualitativa das águas subterrâneas de Fortaleza, Ceará. Estudos Geológicos vol. 26, 2016. Departamento de Geologia/UFC, Fortaleza/Ceará. Disponível em:

https://www3.ufpe.br/estudosgeologicos/paginas/edicoes/2016262/2016262t05.pdf>. Acesso em 17 de Julho de 2019.

HIRATA, C. A. Ricardo; FERREIRA, Luciana M. R. Os aquíferos da bacia hidrográfica do alto Tietê: Disponibilidade hídrica e Vulnerabilidade à poluição. Revista brasileira de geociências, vol. 31. Março de 2001.

IBGE, Instituto Brasileiro de Geografia e Estatística. Índice de desenvolvimento humano (IDH) nos anos: 2010, 2000, 1991. Fonte de tabela da série histórica. Disponível em: <Cartogramashttps://cidades.ibge.gov.br/brasil/pa/belem/pesquisa>. Acesso em 11 de Setembro de 2018.

IEC, Instituto Evandro Chagas. Secretaria de Vigilância em Saúde (SVS); Seção de Meio Ambiente (SM) - Coordenação da Qualidade. Belém-Pará, 2018.

MATTA, Milton Antônio da Silva. Fundamentos hidrogeológicos para a gestão integrada dos recursos hídricos da região de Belém/Ananindeua - Pará, Brasil. 2002. 292f. Tese (doutorado) - Universidade Federal do Pará, Centro de Geociências, Belém/PA. 2002.

MINISTÉRIO DA SAÚDE. PORTARIA № 2.914, DE 12 DE DEZEMBRO DE 2011. Dispõe sobre os procedimentos de controle e de vigilância da qualidade da água para consumo humano e seu padrão de potabilidade. Disponível em: < http://site.sabesp.com.br>. Acesso em 15/01/18. 
PIRATOBA, Alba Rocio Aguilar; RIBEIRO, Hebe Morganne Campos; MORALES, Gundisalvo Piratoba; GONÇALVES, Wanderson Gonçalves. Caracterização de parâmetros de qualidade da água na área portuária de Barcarena, PA, Brasil. Rev. Ambiente. Água vol. 12 n. 3 Taubaté - Mai / Jun. 2017.

SANTOS, Verônica Jussara Costa. Modelo de processo participativo de enquadramento aplicado a bacias hidrográficas urbanas: bacia do Tucunduba. Dissertação (Mestrado) - Universidade Federal do Pará, Instituto de Tecnologia, Programa de Pós-Graduação em Engenharia Civil. Belém, 2010.

SILVA, Joilson José Fonseca da; MIGLIORINI, Renato Blat. Caracterização das Águas subterrâneas do aquífero Furnas na região sul do Estado de Mato Grosso. São Paulo, UNESP, Geociências, v. 33, n. 2, p.261-277, 2014.

SILVA, Rita de Cássia Assis da; ARAÚJO, Tânia Maria de. Qualidade da água do manancial subterrâneo em áreas urbanas de Feira de Santana (BA). Ciência e Saúde coletiva. Artigo apresentado em 8/9/2003. Aprovado em 28/11/2003. Versão final apresentada em 01/12/2003. Disponível em: < http://www.scielo.br/pdf/csc/v8n4/a23v8n4>. Acesso em 17 de Julho de 19.

SOUZA, Valéria Carvalho de Assis Brasil, SOARES, Vinicius Prates, MACIEL, Anderson Véras; KEMERICH, Pedro Daniel da Cunha. Qualidade da água subterrânea do bairro Perpétuo Socorro de Santa Maria - RS. Disc. Scientia. Série: Ciências Naturais e Tecnológicas, S. Maria, v. 5, n. 1, p. 31-49, 2004. 31 ISSN 1519-0625. 


\section{ANEXO 1}

PERFIL BASE PARA O MODELO DE CONTAMINAÇÃO

COSANPA SETOR 7: Sistema de abastecimento Terra Firme.

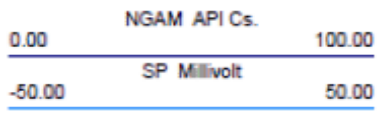

\begin{tabular}{lrr}
1.00 & LON Ohm M. & 10000.00 \\
\hline 1.00 & SPR Ohm & 10000.00 \\
\hline 100 & SHN Ohm M. & 10000.00
\end{tabular}

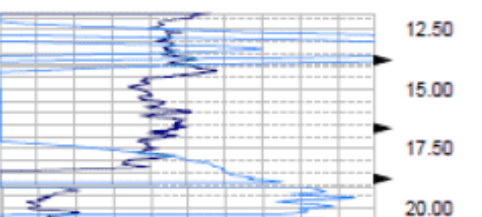

$1.00 \quad 10000.00$
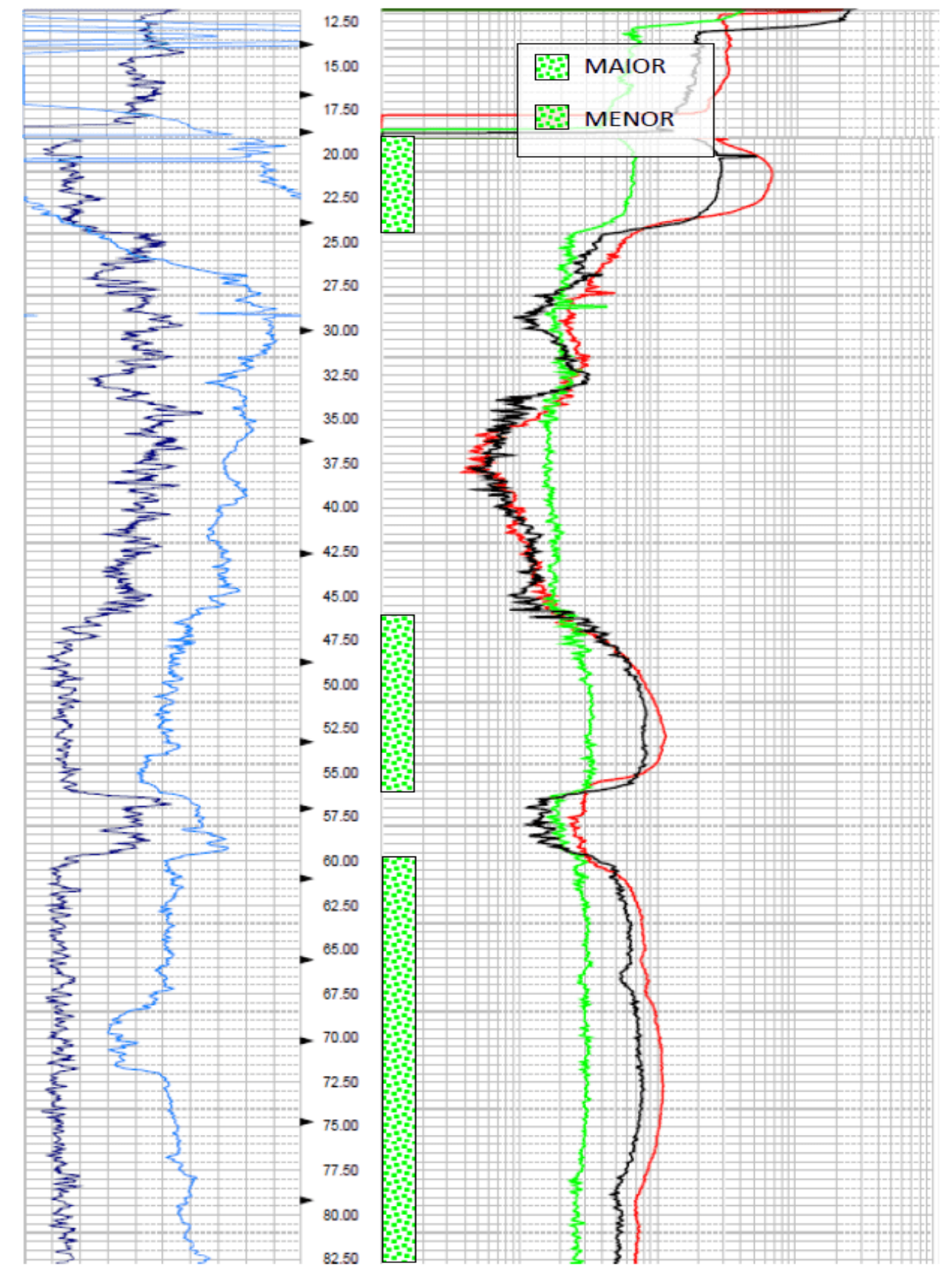

RC: 52358

Disponível em: https://www.nucleodoconhecimento.com.br/meio-ambiente/aguas-de-pocos 


\section{APÊNDICE - REFERÊNCIAS DE NOTA DE RODAPÉ}

3. Organización Panamericana de la Salud (OPS).

4. No anexo 1 tem-se o perfil produzido a partir da perfilagem geofísica de um poço anterior a instalação dos filtros, no setor 7 , sistema de abastecimento da COSANPA, localizado no bairro da Terra Firme (Belém-Pará), este serviu de base para a confecção das camadas litológicas do modelo de contaminação por efluentes diversos.

Enviado: Dezembro, 2019.

Aprovado: Junho, 2020. 